\title{
PENGARUH LATIHAN STABILISASI POSTURAL TERHADAP KESEIMBANGAN STATIS DAN DINAMIS PADA PASIEN PASCA STROKE
}

\author{
*Indah Pramita ${ }^{1}$, Setiawan ${ }^{2}$, Saifudin Zuhri ${ }^{2}$ \\ ${ }^{1}$ Program Studi Fisioterapi, Fakultas Ilmy Kesehatan, Sains dan Teknologi, Universitas Dhyana Pura, \\ Badung, Bali. \\ ${ }^{2}$ Program Studi DIV Fisioterapi, Poltekkes Surakarta \\ *Email : kd.pramita@gmail.com
}

\begin{abstract}
ABSTRAK
Kasus stroke banyak dijumpai di lapangan, dimana penanganan pada pasien pasca stroke hanya menitik beratkan pada kemampuan motorik dan kurang memperhatikan kontrol postural. Sedangkan pada pasien pasca stroke memiliki masalah dengan kontrol postural yang berfungsi mengontrol posisi badan agar tetap tegak. Adanya masalah tersebut menghambat gerakan pada pasien pasca stroke dan mengakibatkan bertambahnya gangguan keseimbangan. Penelitian ini bertujuan untuk mengetahui manfaat latihan stabilisasi postural terhadap perbaikan keseimbangan statis dan dinamis pada pasien pasca stroke. Rancangan penelitian one group pre-test and posttest design dengan sampel sebanyak 6 orang yang diberikan latihan stabilisasi postural sebanyak 3x/minggu selama 1 bulan. Hasil Penelitian FRT sebelum perlakuan didapatkan rerata \pm SD sebesar $19,67 \pm 6,28$ sedangkan rerata \pm SD FRT setelah perlakuan sebesar 25,50 $\pm 5,28$ dan $p=0,004(p<0,05)$. Hal ini menunjukkan ada pengaruh antara latihan stabilisasi postural terhadap keseimbangan statis pada pasien pasca stroke. Hasil TUG test sebelum perlakuan didapatkan rerata \pm SD sebesar $31,17 \pm 1,82$ sedangkan rerata \pm SD TUG test setelah perlakuan sebesar 18,50 $\pm 5,17$ dan $p=0,027(p<0,05)$. Data ini juga menunjukkan ada pengaruh antara latihan stabilisasi postural terhadap keseimbangan dinamis pada pasien pasca stroke. Latihan stabilisasi postural meningkatkan keseimbangan statis dan dinamis pada pasien pasca stroke.
\end{abstract}

Kata kunci: Latihan, Keseimbangan, Stroke

\begin{abstract}
Many cases of stroke in the field, where the handling of post-stroke patients only focuses on motor skills and lack of attention to postural control. While in post-stroke patients have problems with postural control that controls the position of the body to remain upright. The existence of these problems hamper the movement in post-stroke patients and lead to increased disturbance of balance. This study aims to know the benefits of postural stabilization exercises to improve static and dynamic balance in patients with post stroke. This was an experimental pre using the design of a one group pre-test and post-test design. The number of subjects as many as 6 people, get as much 3x/minggu postural stabilization exercises for 1 month. Result of FRT before treatment obtained a mean $\pm S D$ of $19.67 \pm 6.28$ while the mean $\pm S D$ FRT after treatment for $25.50 \pm 5.28$ and $p=0.004$ ( $p<0.05$ ). It shows atients with post stroke. Results TUG test before and after treatment. TUG test results obtained before treatment the mean $\pm S D$ of $31.17 \pm 1.82$ while the mean $\pm S D$ TUG test after treatment for $18.50 \pm 5.17$ and $p=0.027$ ( $p<0.05)$. It means there is influence between postural stabilization exercises on dynamic balance in patients with post stroke.The postural stabilization exercises enhance static and dynamic balance in patients with post stroke.
\end{abstract}

Keywords: Exercise, balance, Stroke 


\section{PENDAHULUAN}

Stroke adalah cedera vaskular akut pada otak dimana serangan terjadi secara mendadak dan berat pada pembuluhpembuluh darah otak yang mengakibatkan kematian jaringan otak secara permanen (Feigin, 2006).

Stroke menimbulkan berbagai macam problematika, diantaranya: (1) gangguan sensomotorik, (2) gangguan kognitif/memori, (3) gangguan psikiatrik atau emosional (Kuntono, 2010). Salah satu problematik yang paling mendasar pada pasien pasca stroke adalah adanya gangguan sensomotorik.

Gangguan sensomotorik pasca stroke mengakibatkan gangguan keseimbangan termasuk kelemahan otot, penurunan fleksibilitas jaringan lunak, serta gangguan kontrol motorik dan sensorik. Fungsi yang hilang akibat gangguan kontrol motorik pada pasien pasca stroke mengakibatkan hilangnya koordinasi, hilangnya kemampuan merasakan keseimbangan tubuh dan postur (kemampuan untuk mempertahankan posisi tertentu).

Gangguan keseimbangan berdiri pada pasien pasca stroke berhubungan dengan ketidakmampuan untuk mengatur perpindahan berat badan dan kemampuan gerak otot yang menurun sehingga keseimbangan tubuh menurun. Dengan adanya problematik tersebut menyebabkan pasien pasca stroke mengalami gangguan dalam melakukan aktifitas fungsional. Untuk melakukan aktifitas fugsional dengan baik dibutuhkan suatu keseimbangan yang baik pula (Irfan, 2009).

Keseimbangan adalah kemampuan untuk mempertahankan keseimbangan tubuh ketika ditempatkan di berbagai posisi. Pada pasien pasca stroke adanya gangguan keseimbangan akan mengakibatkan mereka sulit dalam melakukan aktivitas fisik.

Pendekatan terapi pada pasien stroke sangat banyak macam dan metodenya. Pendekatan Bobath, Johnstone, Root, Propioceptive Neuromuscular Fascilitation $(P N F)$, Brunnstrom, Constraint Induced Movement Therapy (CIMT) dan Motor Relearning Programme (MRP) merupakan beberapa metode yang sering digunakan dalam penanganan pasien stroke. Pendekatan-pendekatan tersebut di dalamnya terdapat suatu latihan yang menekankan pada stabilisasi tulang belakang dan ekstremitas.
Stabilisasi didefinisikan sebagai kemampuan untuk mengkontrol posisi dan pergerakan dari batang tubuh (trunk) di atas panggul dan ekstremitas untuk memudahkan produksi yang optimum, transfer dan kontrol kekuatan (force) dalam bergerak. Pada pasien pasca stroke kemampuan dalam mengontrol pergerakan dari batang tubuh (trunk) dan ekstremitas mengalami gangguan. Dengan dilakukan latihan stabilisasi diharapkan dapat meningkatkan kekuatan dari otot inti yang bertanggung jawab untuk menjaga stabilisasi tulang belakang (vertebrae), serta meningkatkan kekuatan dari ektremitas atas dan ekstremitas bawah bagian tubuh yang lemah, sehingga dapat meningkatkan keseimbangan dan koordinasi pada pasien pasca stroke.

Hal tersebut sesuai dengan permasalahan yang dialami oleh pasien pasca stroke, dimana pada pasien pasca stroke terjadi penurunan kekuatan otot inti, penurunan kekuatan ekstremitas dan terjadi penurunan dalam kontrol postural yang mengakibatkan adanya gangguan keseimbangan.

Kenyataan di lapangan penanganan pada pasien pasca stroke hanya menitik beratkan pada kemampuan motorik dan kurang memperhatikan kontrol postural. Sedangkan pada pasien pasca stroke memiliki masalah dengan kontrol postural yang berfungsi mengontrol posisi badan agar tetap tegak. Adanya masalah tersebut menghambat gerakan pada pasien pasca stroke dan mengakibatkan bertambahnya gangguan keseimbang.

\section{METODE PENELITIAN \\ Ruang Lingkup Penelitian}

Penelitian ini dilaksanakan di Rumah Sakit Angkatan Laut Dr. Ramelan Surabaya pada tanggal 3 Nopember 2010 sampai dengan 26 Nopember 2010.

\section{Sampel}

Subyek penelitian adalah pasien pasca stroke yang dikonsultasikan ke Instalasi Rehabilitasi Medik RSAL Dr. Ramelan Surabaya pada tanggal 3 Nopember 2010 sampai dengan 26 Nopember 2010 yang mendapat program latihan dan memenuhi kriteria inklusi sebagai berikut: (1) keadaan umum baik dan tensi stabil, (2) mampu berjalan, (3) skala asworth nilai 1-2, (4) kooperatif dan mengerti perintah verbal, (5) 
bersedia mengikuti latihan dalam penelitian ini sampai selesai

Sedangkan kriteria eksklusi adalah sebagai barikut: (1) secara klinis ada gagal jantung (EKG abnormal), (2) hipertensi berat (>200/120), (3) febris (temp >38 $>$ C) dan gangguan hemodinamik, (4) ada gangguan penglihatan maupun pendengaran (5) amputasi pada tungkai, (6) artitis dan nyeri pada ekstrimitas bawah, (7) gangguan vestibular, (8) gangguan otak yang lain misalnya Parkinson.

Kriteria drop-out dari penelitian ini adalah subyek penelitian yang tidak melakukan latihan lebih dari sekali setiap minggunya.

\section{Variabel dan Definisi Operasional Pasca stroke}

Pasca stroke adalah seseorang atau pasien yang telah mengalami stroke yang, mampu miring, mampu duduk secara mandiri, dan mampu berjalan baik dengan ataupun tanpa alat bantu serta memiliki nilai asworth 1-2 dan tidak mengalami gangguan penglihatan.

\section{Latihan stabilisasi postural}

Latihan stabilisasi postural adalah latihan yang menggunakan prinsip mengoptimalkan otot postural (thruk dan abdominal. Dengan dilakukan latihan stabilisasi postural diharapkan dapat meningkatkan kekuatan dari otot inti yang bertanggung jawab untuk menjaga stabilisasi tulang belakang (vertebrae), serta meningkatkan kekuatan dari ektremitas atas dan ekstremitas bawah bagian tubuh yang lemah, sehingga dapat meningkatkan keseimbangan dan koordinasi pada pasien pasca stroke (Stecyk, 2008).

\section{Keseimbangan}

Keseimbangan adalah kemampuan untuk mempertahankan keseimbangan tubuh ketika ditempatkan di berbagai posisi. Keseimbangan diukur dengan FRT untuk mengukur keseimbangan statis sedangkan TUG test untuk mengukur keseimbangan dinamis.

\section{HASIL DAN PEMBAHASAN}

Analisis hasil FRT sebelum dan setelah latihan stabilisasi postural

Analisis hasil penelitian ini dapat di lihat melalui perbandingan hasil FRT sebelum dan setelah perlakuan. Hasil FRT sebelum perlakuan didapatkan rerata \pm SD sebesar $19,67 \pm 6,28$ sedangkan rerata \pm SD FRT setelah perlakuan sebesar $25,50 \pm 5,28$. Kalau dilihat dari rerata keseimbangan statis sebelum dan setelah perlakuan maka ada peningkatan keseimbangan statis yang dibuktikan dengan hasil FRT sebesar 5,83 $\mathrm{cm}$. Hal ini menunjukkan peningkatan yang cukup besar, yang dapat dilihat dari tabel 1 di bawah ini.

Tabel 1. Analisa hasil FRT sebelum \& setelah perlakuan

\begin{tabular}{llll}
\hline Statistik & FRT sebelum & $F R T$ setelah & Selisih FRT \\
\hline Min & 12 & 17 & 5 \\
Max & 30 & 32 & 2 \\
Median & 18,5 & 25 & 6,5 \\
Mean & 19,67 & 25,50 & 5,83 \\
Std. Deviation & 6,28 & 5,28 & 1 \\
\hline
\end{tabular}

Analisis hasil TUG test sebelum dan setelah latihan stabilisasi postural

Analisis hasil penelitian ini dapat di lihat melalui perbandingan hasil TUG test sebelum dan setelah perlakuan. Hasil TUG test sebelum perlakuan didapatkan rerata \pm SD sebesar $31,17 \pm 1,82$ sedangkan rerata \pm SD TUG test setelah perlakuan sebesar $18,50 \pm 5,17$. Kalau dilihat dari rerata keseimbangan dinamis sebelum dan setelah perlakuan maka ada peningkatan keseimbangan dinamis yang dibuktikan dengan hasil TUG test sebesar 12,67. Hal ini menunjukkan peningkatan yang cukup besar, yang dapat dilihat dari tabel 2 di bawah ini. 
Tabel 2. Analisa hasil tug test sebelum \& setelah perlakuan

\begin{tabular}{ccccc}
\hline Statistik & $\begin{array}{c}\text { TUG } \\
\text { sebelum }\end{array}$ & test & $\begin{array}{c}\text { TUG } \\
\text { setelah }\end{array}$ & $\begin{array}{c}\text { Selisih } \\
\text { TUG test }\end{array}$ \\
\hline Min & 15 & 11 & 4 \\
Max & 67 & 26 & 41 \\
Median & 26,5 & 19 & 7,5 \\
Mean & 31,17 & 18,50 & 12,67 \\
Std. & 1,82 & 5,17 & 3,35 \\
Deviation & & & \\
\hline
\end{tabular}

ANALISIS STATISTIK

Uji Normalitas

Uji normalitas FRT sebelum dan setelah latihan stabilisasi postural

Pada penelitian ini, data yang didapat sesuai dengan Shapiro-wilk test untuk nilai hasil kedua pengukuran FRT sebelum dan setelah perlakuan memiliki nilai $p \geq 0,05$. Dengan demikian dapat disimpulkan bahwa data pengukuran keseimbangan statis adalah berdistribusi normal. Hal ini dapat dilihat berdasarkan tabel 3 di bawah ini:

Tabel 3. Hasil Uji Normalitas FRT Sebelum Dan Setelah Latihan Stabilisasi Postural

\begin{tabular}{lrrr}
\hline & \multicolumn{3}{c}{ Shapiro-wilk } \\
& Statistic & $\mathrm{n}$ & $p$ \\
\hline FRT pre test & 0,97 & 6 & 0,86 \\
FRT post test & 0,95 & 6 & 0,73 \\
\hline
\end{tabular}

Uji normalitas TUG sebelum dan setelah latihan stabilisasi postural

Pada penelitian ini, data yang didapat sesuai dengan Shapiro-wilk test untuk nilai hasil pengukuran TUG sebelum memiliki nilai $p=0,01(p<0,05)$ dan nilai TUG sesudah perlakuan memiliki nilai $p=0,99(p$ $\geq$ 0,05). Dengan demikian dapat disimpulkan bahwa data pengukuran keseimbangan statis adalah berdistribusi tidak normal. Hal ini dapat dilihat berdasarkan tabel 4 di bawah ini:

Tabel 4 Hasil uji normalitas tug sebelum dan sesudah latihan stabilisasi postural

\begin{tabular}{lccc}
\hline & \multicolumn{3}{c}{ Shapiro-Wilk } \\
& Statistic & $\mathrm{n}$ & $p$ \\
\hline TUG pre test & 0,73 & 6 & 0,01 \\
TUG post $t$ test & 0,99 & 6 & 0,99
\end{tabular}

\section{Uji hipotesis}

Pengaruh Latihan Stabilisasi Postural Terhadap Keseimbangan Statis Pasien Pasca Stroke

Setelah dilakukan uji normalitas data dengan Shapiro-wilk test, data yang diperoleh adalah berdistribusi normal, maka dilakukan uji pengaruh menggunakan paired t-test. Sesuai dengan tujuan penulisan penelitian ini, dilakukan uji pengaruh sebelum dan sesudah latihan untuk mengetahui manfaat latihan stabilisasi postural terhadap perbaikan keseimbangan statis pasien pasca stroke. Dari hasil uji pengaruh latihan stabilisasi postural terhadap keseimbangan statis yang dilakukan dengan paired t-test diperoleh nilai $p=0,004(p \leq 0,05)$ yang berarti ada pengaruh antara latihan stabilisasi postural terhadap keseimbangan statis pada pasien pasca stroke.

Latihan stabilisasi postural berfungsi untuk meningkatkan kekuatan otot ekstremitas dan juga kekuatan otot trunk serta mencegah cedera (William, 2006). Hal itu sesuai dengan pendapat yang dikemukakan oleh Smooth (2005), bahwa latihan stabilisasi akan menghasilkan koordinasi serta kekuatan antara otot perut dan otot punggung sehingga akan membentuk stabilisasi dari trunk dan memperbaiki posisi tumpuan di base of support yang memudahkan terjadinya pergerakan dari ekstremitas. Dengan adanya otot postural yang adekuat akan dapat memberikan stabilisasi yang baik dan 
mampu mempertahankan posisi dalam keadaan seimbang. Hal tersebut terjadi karena otot postural yang kuat akan mampu menyeimbangkan antara BoS dan CoG, sehingga akan didapat suatu keadaan yang seimbang (Irfan, 2010).

Pada pasien pasca stroke terjadi perubahan $\mathrm{CoG}$, dimana CoG menjadi lebih rendah yang dapat dibuktikan dengan observasi dimana pada pasien pasca stroke postur cenderung menjadi membungkuk, sendi panggul menekuk yang akhirnya memposisikan CoG lebih rendah (Irfan, 2010). Hal itu sesuai dengan pengamatan peneliti terhadap subjek penelitian dimana hampir semua subjek memiliki postur membungkuk dengan panggul menekuk dan lutut menekuk. Dengan postur tersebut pasien pasca stroke terlihat kesulitan mempertahankan posisi tegak. Namun, setelah satu bulan dilakukan latihan stabilisasi postural terlihat postur pasien sedikit berubah. Lutut yang awalnya cenderung menekuk dan terlihat tidak stabil setelah dilakukan latihan terlihat lebih lurus dan terlihat lebih stabil. Begitu juga pada sendi panggul terlihat lebih lurus dan stabil. Sehingga pasien mampu lebih lama mempertahankan posisi tegak. Hasil dari uji pengaruh seperti terlihat pada tabel 5 dibawah ini:

Tabel 5 Tabel uji pengaruh latihan stabilisasi postural terhadap keseimbangan statis pasien pasca stroke

\begin{tabular}{|c|c|c|c|c|}
\hline Alat ukur & & Mean \pm SD & $\mathrm{t}$ & \\
\hline FRT pre & 6 & $19,67 \pm 6,28$ & $-5,13$ & 0,0 \\
\hline FRT post & & $25,50 \pm 5,28$ & & 04 \\
\hline
\end{tabular}

Pengaruh latihan stabilisasi postural terhadap keseimbangan dinamis pasien pasca stroke

Setelah dilakukan uji normalitas data dengan Shapiro-wilk test, data yang diperoleh adalah data berdistribusi tidak normal, maka dilakukan uji pengaruh menggunakan wilcoxon test. Sesuai dengan tujuan penulisan penelitian ini, dilakukan uji pengaruh sebelum dan sesudah latihan untuk mengetahui manfaat latihan stabilisasi postural terhadap perbaikan keseimbangan dinamis pasien pasca stroke. Dari hasil uji pengaruh latihan stabilisasi postural terhadap keseimbangan dinamis yang dilakukan dengan wilcoxon diperoleh nilai $p$ $=0,027(p \leq 0,05)$ yang berarti ada pengaruh antara latihan stabilisasi postural terhadap keseimbangan dinamis pada pasien pasca stroke.

Menurut penelitian Navalta, James dan Hrncir Stephen (2007) latihan stabilisasi dapat meningkatkan produksi laktat, meningkatkan aliran darah dan meningkatkan kekuatan otot - otot inti. Meningkatnya kekuatan otot inti atau otot postural merupakan komponen yang sangat penting dalam membentuk keseimbangan. Salah satu faktor pengontrol keseimbangan adalah respon dari otot-otot postural yang sinergis. Adanya respon otot postural yang sinergis akan memungkinkan seseorang melakukan perubahan posisi dengan seimbang.

Selain meningkatkan kekuatan otot postural, latihan stabilisasi postural juga dapat meningkatkan kekuatan otot panggul dan otot tungkai, karena latihan yang diterapkan tidak hanya melatih otot postural saja tetapi juga melatih fungsi dari ekstremitas bawah. Kekuatan otot dari kaki, lutut serta pinggul yang adekuat dapat mempertahankan keseimbangan tubuh saat adanya gaya dari luar. Kekuatan otot tersebut berhubungan langsung dengan kemampuan otot untuk melawan gaya gravitasi serta beban eksternal lainnya yang secara terus menerus mempengaruhi posisi tubuh (Irfan, 2010).

Dengan adanya kerja yang sinergis dari otot postural, otot panggul dan otot tungkai akan didapat kemampuan melangkah yang baik dengan kata lain didapatkan sebuah keseimbangan yang baik saat berjalan. Hal ini sesuai dengan pendapat Mackay-Lyons, (2002) yang mengatakan bahwa berjalan merupakan kemampuan motorik yang membutuhkan koordinasi dari trunk dan kekuatan otot ekstremitas atas dan ekstremitas bawah.Hasil dari uji pengaruh seperti terlihat pada tabel 6 dibawah ini: 
Tabel 6 Tabel uji pengaruh latihan stabilisasi postural terhadap keseimbangan dinamis pasien pasca stroke

\begin{tabular}{crrc}
\hline Alat ukur & Mean \pm SD & Z & $p$ \\
\hline TUG pre & $31,17 \pm 1,82$ & $-2,21$ & 0,027 \\
TUG post & $18,50 \pm 5,17$ & & \\
\hline
\end{tabular}

\section{KESIMPULAN}

Kesimpulan dari penelitian ini adalah bahwa latihan stabilisasi postural meningkatkan keseimbangan statis dan dinamis pada pasien pasca stroke.

\section{SARAN}

Adapun saran yang dapat penulis sampaikan antara lain: (1) Dari awal sejak masa perawatan sampai masa golden period hendaknya pasien pasca stroke diberikan masukan yang benar yaitu posisi, gerakan dan pola yang benar, (2) Latihan stabilisasi postural hendaknya diberikan pada masa golden period untuk mendapatkan hasil yang lebih baik, (3) Dilakukan penelitian lebih lanjut yang sejenis dengan jumlah subyek yang lebih banyak, waktu yang lebih lama, ditambahkan kelompok pembanding, dan disertakan hasil CT-scan atau MRI.

\section{DAFTAR PUSTAKA}

Feigin, Valery. (2006). Stroke (Edisi kedua). PT Bhuana Ungu Populer. Jakarta.

Heru Purbo Kuntono. (2010). Pemeriksaan TF C Pusat, Dalam Handout Kuliah FT C Pusat Jurusan DIV Fisioterapi. Politeknik Kesehatan Surakarta, Surakarta.
Irfan, 2009; Keseimbangan Pada Stroke, Diakses tanggal 10/06/2010, dari http://infostroke.wordpress.com/kesei mbangan-pada-stroke/

Mackay-Lyons, M. (2002). Central pattern generation of human locomotion. Dalam Bobath Concept Theory and Clinical Practise in Neurological Rehabilitation. United Kingdom.

Navalta, W. James and Hrncir P. Stephen. (2007). Core Stabilization Exercises Enhance Lactate Clearance Following High Intensity Exercise. Journal of Strength and Conditioning Research.

Smooth, Smith. (2005). Core Stability Exercise. Diakses tanggal 10/06/2010 Available from: http://hubpages.com/hub/corestability-exercise

Stecyk, D Shane. (2008). The Missing Link: Core Training Terintegrasi. NSCA's Performance Training Journal. Colorado.

Williams, Chat. (2008). Core Training Dengan Domed Device. NSCA's Performance Training Journal Colorado 